Estudios Constitucionales, Año 13, № 2, 2015, pp. $485-496$

ISSN 07180195

Centro de Estudios Constitucionales de Chile Universidad de Talca

"Entrevista a Jorge Tapia Valdés"

Liliana Galdámez Zelada

\title{
ENTREVISTA A JORGE TAPIA VALDÉS
}

\section{Por Liliana GaLdÁmez ZeladA ${ }^{1}$}

Don Jorge Tapia Valdés es Licenciado en Ciencias Jurídicas y Sociales de la Universidad de Chile, tiene una Maestría en Derecho por la Universidad de Yale, es Doctor en Derecho por la Universidad de Erasmus Rotterdam (Holanda). Ha desarrollado una larga trayectoria en funciones públicas, destacando como Ministro de Justicia y Educación del gobierno del Presidente Salvador Allende Gossens. Ha sido Embajador de Chile ante los Países Bajos e Israel y se desempeñó como Intendente de la Región de Tarapacá. En el ámbito académico, el Profesor Tapia ha escrito sobre diversos temas, entre ellos: Derecho Parlamentario, Seguridad Nacional, Estado subsidiario, Descentralización, Integración y paradiplomacia. También se ha destacado en la docencia universitaria como Profesor en la Facultad de Derecho de la Universidad de Chile, de la Universidad de la República, de la Universidad Arturo Prat, Ohio State University, Universidad del Zulia y Erasmus Universiteit Rotterdam, entre otras. Fue Secretario de la Comisión de Constitución, Legislación y Justicia del Senado, donde trabajó por 18 años.

La destacada trayectoria de don Jorge Tapia Valdés como hombre público $\mathrm{y}$ actor de nuestra historia republicana motiva el interés por esta entrevista que esperamos contribuya con nuevas luces al incipiente proceso constituyente que se inicia en Chile.

L.G.: ¿Cuáles recuerda usted como la o las principales reformas a la Constitución de 1925 y por qué?

JT.: Recuerdo como importantes reformas de la Constitución de 1925, la que elevó a rango constitucional la Contraloría General de la República, las de reforma agraria y de modernización del Estado y de la función legislativa del período de Eduardo Frei; la de garantías constitucionales que abrió paso a la presidencia de Salvador Allende y la reforma que permitió la nacionalización del

1 Liliana Galdámez Zelada es Licenciada en Ciencias Jurídicas y Sociales de la Universidad de Chile y Doctora en Derecho por la Universidad de Valladolid. Esta entrevista ha contado con la valiosa contribución de Manuel Yáñez Espinoza, alumno de $5^{\circ}$ año de la carrera de Derecho de la Facultad de Ciencias Jurídicas y Sociales de la Universidad de Talca y Director Ejecutivo del Centro de Estudios Democracia y Justicia de la misma universidad. 
cobre durante el período de este último. Importantes por razones que resultan obvias, todas ellas fueron realizadas por el poder constituyente constituido y en medio de tranquilidad política, aun de aprobación unánime, salvo la de garantías constitucionales, durante cuyo estudio, como se ha sabido después, se movieron en contra oscuras fuerzas nacionales y norteamericanas de derecha. Esta fue la regla general y permanente entre 1925 y 1973, y luego, de 1989 hasta el comienzo del actual período presidencial, en donde ha fallado la interacción acostumbrada entre partidos políticos, instituciones y sociedad civil.

L.G.: ¿Cómo valora usted las secuelas del golpe de Estado del 11 de septiembre de 1973 ?

J.T.: El régimen militar destruyó en un par de meses las bases jurídicas, morales y económicas gracias a las cuales el país estaba construyendo, desde 1938 y a la luz de premisas democráticas, un Estado de Bienestar, o al menos basado en una economía social de mercado.

Las reformas constitucionales de la década de 1960 para llevar adelante la reforma agraria y nacionalizar el cobre, o el Estatuto de Garantías de 1971, son demostraciones de que la CPR lo era de un Estado Social "in the making" y que en ese período la Constitución no era un obstáculo sino un instrumento de cambio social.

La dictadura reemplazó este proyecto, cuyo avance llamaba la atención internacional, por una forma de Estado Mínimo y Subsidiario implantado por vía experimental en un laboratorio conformado por toda una nación, que se nutría del pensamiento de Friedrich Hayek y Milton Friedman, a partir de ese contubernio neo-conservador-liberal tan bien entretejido por Jaime Guzmán.

El choque, en 1973, entre fuerzas e ideas revolucionarias y contrarrevolucionarias generó un régimen de gobierno y forma de Estado definible como de "excepción y emergencia permanente", asentado en el rechazo del principio mayoritario como modelo legítimo de toma de decisiones, que fue reemplazado por un sistema de enclaves autoritarios e instituciones contramayoritarias. (¿Se acuerda de Karl Schmitt?)

Puede en realidad afirmarse que la Constitución de 1980 expropió a los chilenos la soberanía popular al tiempo que privatizaba la riqueza nacional, y reemplazaba el tipo de Estado Social por uno de capitalismo salvaje.

L.G.: ¿Qué rol cumplió la Constitución de 1980 en ese proceso y cómo afectó al retorno a la democracia?

J.T.: La Carta Fundamental pasó en realidad a ser un mero reflejo de las correlaciones de fuerza en el tráfico entre los poderes económicos, nacionales e 
internacionales, imponiendo por medios violentos y a nivel constitucional las bases de un determinado orden económico.

Al comenzar en 1990 la transición a la democracia el país presentaba una enorme deuda social y laboral, además de infraestructural, ecológica y ambiental, y empezaba a singularizarse como una economía de alta eficiencia en materia de crecimiento del PIB, pero también y simultáneamente, en una usina de desigualdad, es decir, era un caso de fuerte crecimiento económico sin desarrollo.

Ello hacía suponer que al volver la democracia, aunque fuere de modo gradual, habría premura, imaginación y voluntad para disminuir la brecha igualitaria. No resultó así, demostrándose que las barreras, trincheras y campos minados construidos por la contrarrevolución en retirada eran más fuertes y sabios que los demócratas, algunos de los cuales ya estaban cambiando de filosofía económica.

Empezó a ser claro que el ideario neoliberal y neomedievalista que ostentaba la dictadura había calado hondo en las masas, incluyendo la juventud, que hacían alarde de su falta de conocimiento, interés y confianza en los grandes relatos y utopías. Esos jóvenes, y no tan jóvenes, no alcanzaron a enterarse que las limitaciones a la libertad proveniente de la racionalista "iron cage" weberiana son juego de niños comparadas con los muros, frenos y barreras que impone sobre la libertad el capitalismo salvaje y anárquico del período de la globalización neoliberal y posmodernista. Por lo mismo, los asustaba el cambio y no tenían confianza en sus propias ideas.

L.G.: Desde su perspectiva, ¿ha sido reformada en serio la Constitución de 1980 ?

J.T.: Mirado desde el exterior y a la distancia en el tiempo, el proceso de cambio y reforma social, jurídica y política que experimenta desde 2011 la sociedad chilena es escaso, tardío y muy elemental o básico. Estamos en un país que comenzó recién en 1990 la transición hacia la democracia desde un autoritarismo brutal y fundamentalista que trastornó las bases de legitimidad de la estructura y ejercicio del poder, tanto político como de hecho, en nombre de, y gracias a una ideología político-militar como la Doctrina de Seguridad Nacional, de absoluto carácter contrarrevolucionario y amparada en las premisas del cristianismo medieval.

Ni la modernidad ha sido reemplazada por la posmodernidad, ni el Estado de Bienestar por la caridad proselitista. Todos sabemos que se requieren muchos y urgentes cambios en materia de educación, salud, vivienda, derechos e igualdad de género, derechos de tercera generación, partiendo por el reconocimiento de los pueblos indígenas y la elevación de sus grados de autonomía administrativa libertades sexuales o de consumo no dañino, etc. 
L.G.: Por favor, cuéntenos un poco su opinión sobre las primeras reformas a la Constitución del 80, me refiero a las de 1989.

J.T.: Factores circunstanciales jugaron un rol en el proceso de formación de consenso entre oposición-gobierno alcanzado en 1989 para introducir importantes cambios a la Constitución de 1980. Me refiero a la opinión e información entregada meses antes por este profesor, vía la Revista "Cauce", relativa a un error técnico constitucional cometido por los redactores de la Constitución de 1980 al no incluir en el texto del artículo 127 el propio artículo 127, que establece los quórum con que deben aprobarse las modificaciones a los capítulos que indica, además del respectivo capítulo.

Durante casi diez años mantuve en absoluta reserva el hallazgo que había hecho y que, a falta de publicaciones sobre el punto, al parecer no fue notado y tomado en cuenta por los colegas. De haberse percatado de tal error, los hombres del dictador habrían solucionado el problema en una semana, decretando la correspondiente reforma constitucional.

En efecto, es una norma fundamental de técnica legislativa, como se desprende de la lógica jurídica y del derecho comparado, que una disposición que establece el procedimiento y quórum para modificar la legislación debe tener al menos la misma jerarquía que los textos de mayor rango a que serán aplicables sus normas. En concreto, en el caso de la Constitución de 1980, el artículo 127 dejaba sujeta al quórum ordinario de reforma constitucional, los 3/5 de los parlamentarios en ejercicio, su propia modificación, en circunstancias de que ese quórum debía ser el de 2/3. Con ello, una de las principales barreras contramayoritarias quedaba expuesta al principio mayoritario, algo que sin duda hizo pensar a los partidarios del régimen dictatorial que el futuro de la Carta Fundamental no estaba asegurado.

L.G.: Fue entonces un hallazgo trascendente y que condicionó el proceso de reformas del 89. En definitiva, ¿se ha superado la Constitución de 1980?

J.T.: Lo anterior permite entender por qué opino que el cambio y reforma han sido en los últimos 25 años escasos y frustrantes. A partir de 2011, cuando la velocidad del proceso de cambio y reforma parece hacerse más fuerte, complejo y rápido, lo que produciría inestabilidad, inseguridad y confusión, estamos en realidad ante un espejismo hecho más verosímil por la antipatriótica y desestabilizante crítica de la derecha. Sigue siendo necesaria, por lo visto, una cierta dosis de irracionalismo, -como en el 68 francés- obcecación y autoconfianza en los sectores jóvenes y más luchadores del país, para que el cambio siga produciéndose y aumente.

L.G.: ¿Qué opina sobre las discusiones en torno al derecho a la educación? 
J.T.: Todas las áreas en que se están produciendo cambios y reformas son importantes, pero nos atrevemos a singularizar como de extrema importancia las que tienen que ver con la educación, la descentralización y la Constitución.

En artículo publicado hace un año: "Hedonismo posmodernista y educación superior. Paradojas de la sociedad del conocimiento" (en Anchustegui I., Esteban (Ed.), "Economía, democracia y valores en un mundo global", PyV Editores, Madrid, 2013), señalé que "El impacto de la globalización y de la sociedad red en el campo específico del trabajo condicionan a su modo el sistema educacional. La filosofía imperante convierte a la educación en un bien público al servicio del capital privado, lo cual sabemos puede disminuir su calidad si faltan controles efectivos. La difusión del trabajo flexible exige un sistema de educación continua y permanente, que garantice el reciclaje constante de los trabajadores. Ello es consecuencia del fin de esa forma tradicional de trabajo vinculada al puesto, cargo y función en una empresa o un servicio público o privado que suponía una relación personalizada y de por vida entre empresa y trabajador.

Mientras la globalización impone sistemas de trabajo flexible -es decir, en buen romance, de tipo precario, sujeto a los vaivenes del mercado y al cambio tecnológico-, la empresa global busca al trabajador capaz de aprender a partir del trabajo, es decir, que tiene más capacidades que las usuales, pudiendo adaptarse a condiciones y exigencias cambiantes gracias a la propia capacidad de innovación y creatividad. Tal trabajador no puede ser fácilmente sustituido por trabajadores de capacidad común, y más baratos, ni por máquinas. Ambas características laborales del período de la globalización se transforman en demandas sobre el sistema educacional que, como se ha expresado, debe realizar las adaptaciones necesarias para crear un sistema general de educación permanente y continua".

L.G.: ¿Qué elementos se deben considerar a la hora de abordar la educación?

J.T.: Hace ya mucho tiempo que es un principio y valor nacional muy poderoso reconocer que "gobernar es educar", y que "educar no es adoctrinar". Por tanto, las líneas de la reforma educacional son identificables y pueden resumirse en la creación de un sistema fundado, a nivel general, en la libertad de enseñanza y en la obligatoriedad y gratuidad de la educación, el fortalecimiento y descentralización de la educación pública, usando, en esta y en la privada, un currículum y una metodología fundados en criterios constructivistas, bajo condiciones que permitan la movilidad del estudiante a partir de la flexibilidad curricular y la integración de las evaluaciones, todo ello sustentado por la capacitación constante del cuerpo de profesores y la capacidad de dirección, gestión y administración del personal a cargo de la institución educacional, que garantice la calidad de la educación por establecimiento. 
L.G.: ¿En todos los niveles de la Educación son aplicables estos criterios?

J.T.: Los mismos criterios recién expuestos son en general aplicables en el campo de la educación superior de pregrado y posgrado, complementados, por su especificidad con nuevos modos de relación entre teoría y práctica -aprender a aprender, a ser, a hacer- y el paso de un modelo focalizado en la enseñanza a otro centrado en el aprendizaje, y de un currículum basado solo en conocimientos a otro fundado en competencias. El aumento de la calidad de la educación superior exige la promoción de los posgrados, y el aumento de la enseñanza virtual, de su internacionalización y de la investigación. En ello deben tomarse en cuenta las características nuevas de la educación superior, es decir, su masificación, el fin de la educación para élites, la diferenciación y la "feminización" de la misma, y la tendencia a la complejización de las universidades.

Las circunstancias de hecho a que se enfrenta el sistema educacional, la identificación, conocimiento y aceptación de los criterios para proceder a su reforma, las soluciones ofrecidas, son parte del conocimiento de los expertos en educación y deberían representar un factor positivo en el esfuerzo de lograr acuerdos para reformas como las que indispensablemente necesita la LOCE heredada de la dictadura.

L.G.: ¿Cómo ve los debates sobre la reforma educacional en Chile hoy?

J.T.: Lo que de hecho ha ocurrido se parece a lo que pasa cuando alguien deja sorpresivamente a oscuras la sala en que se trabaja. ¿Qué pasó para que la reforma educacional chilena produjera más diferencias de opinión hoy que hace un año atrás? Sin aventurar opiniones insostenibles o indebidas, podrían citarse los siguientes factores de falta de acuerdo en la reforma: a) Falta de un proyecto preparado con antelación, técnica y políticamente consensuado, al menos en sus acápites fundamentales; b) falta de conocimiento especializado y experiencia política sectorial en los líderes de la reforma y sus contendientes; c) "izquierdización infantil" de algunos líderes estudiantiles o magisteriales, y d) intervención por vez primera de modo importante de factores económicos, en la forma de un empresariado educacional cuyo fin no es enseñar, sino lucrar con la enseñanza, a quienes no interesa la vigencia de criterios de equidad y calidad, sino de factores que resguarden y aumenten el lucro.

La bien educada gente que forma parte de una o más de las muchas comisiones que ha debido atravesar la reforma educacional debería ya tomar conciencia de la escasa prestancia con que hasta ahora han trabajado, asumir su responsabilidad y hacer un esfuerzo más, ya final, para tomar las grandes, importantes y, sobre todo, conocidas decisiones que requiere la realización de la reforma del sistema educacional de Chile.

L.G.: De cara a la constitución de la democracia en materia de descentralización, ¿̨cuáles son sus perspectivas? 
J.T.: Concluyo con lo más importante de todo hoy por hoy: la reforma constitucional en materia de descentralización. No es que haya que detener la fagocitosis santiaguina.

Parafraseando a Walter Rodney, antes de que llegue el momento en que todos nos preguntemos “¿cómo Santiago subdesarrolló a Chile?”, hay que crear las condiciones para que el resto del país crezca y se desarrolle, y pueda alcanzar las fronteras de bienestar y seguridad que legítimamente le corresponden. Hay suficiente y conocida literatura científica sobre "cómo descentralizar" y cómo parar la centralización creciente del país, la acumulación de poder sobre poder que causa la "desertificación" de las regiones y, al mismo tiempo, enfrentar el complejo de inferioridad de las "élites" regionales.

Se conocen las razones, causas y efectos de la centralización, así como los conceptos e instrumentos de una política integral y masiva contra la centralización. Se conocen incluso los medios y métodos para frenar la incompetencia y corrupción en el área descentralizada. Se cuenta con ejemplos de derecho, política, economía, administración y desarrollo comparados, pero todos estos conocimientos se tratan como inexistentes, como si la descentralización debiere, en virtud de una infantil norma, tener "sabor a empanada y vino tinto".

El más grande paso que ha dado la segunda administración Bachelet ha sido la designación de la Comisión Asesora para la Descentralización, basada en tres pilares: elección democrática y directa del intendente; traspaso de competencias desde el gobierno central a los gobiernos regionales, y reforma del sistema de financiamiento de los gobiernos regionales y municipales. El más grande error del mismo gobierno en la misma materia fue no prestar auténtico oído a las recomendaciones, casi siempre unánimes, hechas por los competentes integrantes de la comisión. Y además, colocando al lado del intendente un criollo "gobernador Regional" nombrado por el Presidente(a) e invitar a los que defienden la re-centralización a "Tirez sur l'Intendent". Se sabe cómo hacerlo, pero no se quiere hacer lo que hay que hacer. Esperemos que ello empiece a cambiar y, sobre todo, que se trabaje en el área de la que depende la autenticidad o el engaño de la descentralización: la descentralizacion fiscal, en materia de poderes para determinar, coordinadamente con Hacienda, las fuentes de ingresos, gastos e inversiones de la región.

Un último consejo: evitar en lo posible trabajar en materia de descentralización con los santiaguinos ministros de Estado y sus altos funcionarios: no más ser nombrados en el cargo, se transforman en cancerberos encerrados en el Palacio de "La Moneda", que ven como una fortaleza contra los "bárbaros" regionales que pretenden tomarse el poder. Y no me hagan recordar mis propias experiencias como intendente de Tarapacá con algunos ministros de la época, cuando el 
Presidente Ricardo Lagos se tomó en serio la descentralización y la generación de liderazgo en las regiones.

L.G.: ¿Es momento de poner frenos o es momento de avanzar en el camino hacia una Constitución democrática?

J.T.: Es tiempo y lugar no para interrumpir el proceso de cambio y reforma, o de moderarlo, sino de acelerarlo. La próxima Constitución debe crear un inteligente y sabio nuevo tipo de Estado Social, porque no necesitamos ni aceptamos trabajadores con los bolsillos vacíos y caras de pedigüeños, sino de ciudadanos libres e informados capaces de ejercer los poderes democráticos que les pertenecen, haciendo verdad que las personas nacen libres e iguales en dignidad y derechos (art. 10 CPR).

L.G.: ¿Usted sugiere algunos contenidos esenciales para la futura Constitución?

J.T.: La actitud que recomendamos asumir ante el proceso de cambio y reforma y la erección de un Estado Social son tanto más importantes y necesarias si simultáneamente tenemos presente que el conjunto de esos cambios es también y además la base de la expansión y renovación de los derechos de ciudadanía y, por tanto, de profundización y autentificación de la democracia y el republicanismo descentralizado. No se trata de repetir la vieja idea y principio de que la ciudadanía y los derechos que comprende o abarca es puro y mero papel si los dueños del poder fáctico son a la vez dueños de la libertad de los ciudadanos cuando ejercen sus derechos activos y pasivos como tales.

Ahora, la época está preludiada, además y como sabemos, por la imperiosa y urgente necesidad de una fuerte descentralización, cuya efectividad supone nuevas estructuras de poder y novedosas formas de división de competencias. Si Chile no tiene pronto una población cuyos miembros vean satisfechas sus necesidades básicas, si los votantes no perciben una disminución del abismo de desigualdad socioeconómica, sentirán que no han alcanzado poder e independencia suficientes para poner fin al abuso.

L.G.: ¿Qué espera del proceso constituyente?

J.T.: En materia de cambio de la Constitución de 1980, y reiterando las cuestiones doctrinales y teóricas expuestas con anterioridad que hacen imperativa la reforma. Nada más oscurecedor que la simple frase con que el Mensaje Presidencial de 21/05/2015 se refiere resumidamente al tema: "En septiembre se iniciará un proceso constituyente abierto a la ciudadanía, bajo el contexto (sic) de un Acuerdo Político Amplio transparente y de cara al país, que permita contar con una nueva Constitución". Su lectura lo deja a uno con el sabor de un decir que poco dice, aunque dejando trasuntar que hay problemas para efectivamente realizar lo que se dice que se va a hacer. Algo así como "Con la Iglesia tocamos 
Sancho". Y eso es tanto o más importante que los quórum de $3 / 5$ o $2 / 3$ y otras argucias contramayoritarias -como el recientemente cambiado sistema electoral binominal minoritario-, si se trata de reformar una Constitución fundada principalmente en importantes valores católicos. Este tipo de obstáculos, nada fácil de sacar a la luz, pueden ser más difíciles de sortear que las normas que establecen quórum contramayoritarios. La suma de ambos obstáculos conduce a magnificar la importancia de las tácticas a emplear al fin de lograr la meta estratégica de la reforma. Ello podría significar que se usen temas y procedimientos que solo por vía de consecuencia indirecta conducen a establecer una nueva norma en materia constitucional.

L.G.: ¿Cree posible que se convoque a una Asamblea Constituyente?

J.T.: Si se quiere perder la batalla reformista y no se planea emplear métodos de acción directa, el plan mejor es intentar, fuera de las reglas del juego, constituir de hecho una Asamblea Constituyente. Hay que tener presente que la Constitución de 1980, especialmente después de las 34 modificaciones de que ha sido objeto, es reconocida como propia de un sistema fundado en el Estado de Derecho, el principio de legalidad, la separación de poderes y funciones y la división de competencias, tutelado todo desde la cima por el Tribunal Constitucional.

Por otra parte, el derecho comparado ofrece más ejemplos de "constituciones rígidas" que "flexibles", de modo que subsanado el problema del sistema binominal, la Constitución chilena pasa a ser simplemente una más de las rígidas. Por último, tengamos presente que el rol principal de la Constitución no es producir el cambio, sino impedirlo o dificultarlo hasta que quede probada que cuantitativa y cualitativamente debe reformarse la ley suprema. Uno puede coincidir con mucho que el uso de este razonamiento y lenguaje es mero histrionismo político y académico, y que la verdadera lucha y campo de batalla es la calle, son los espacios públicos (las demostraciones estudiantiles chilenas o las "mareas" españolas), pero tal alegato no ganará muchos votos. Con todo, ha servido para dejar sentado que la gente reclama cambios, lo que acontece un tanto antes de hacer en verdad los cambios, estos requieren estudio, negociación, y más estudio, en una demostración típica de ejercicio del "arte política".

L.G.: ¿Qué importancia asigna a los consensos en el proceso hacia una Constitución democrática?

J.T.: Por supuesto, nadie ha salido a quemar en un cruce de calles la Constitución de 1980 y a repartir entre los curiosos el texto de una nueva, de 2015. Pero esa es la sensacionalidad con que muchos colegas de la derecha fundamentalista abordan el tema, pretendiendo sentar la idea de que cualquier cambio de la Carta Fundamental no aceptado por ellos es antipatriota y violentista. 
Teniendo presente que esa derecha es experta en sembrar miedo y terror y, luego, en hacerlo realidad, resulta interesante la proposición formulada por la Reforma Democrática (Rodrigo Mora et al.) para modificar la CPR mediante la elección de una Asamblea Constituyente elegida después de modificar los artículos 15 y 32, No 4, en relación con el artículo 128 de la CPR. Puede afirmarse que tal proposición y el procedimiento a seguir, armonizan de modo efectivo las consideraciones tácticas y estratégicas que hay que tener en cuenta. Se ha dicho que tal fórmula reuniría el quórum de 3/5 que la moción o mensaje de reforma necesita para ser aprobada. Algo que obliga a apoyarla mientras no se conozca otro plan aun más inteligente.

L.G.: Finalmente, don Jorge, ¿cree que es importante el mecanismo a través del cual se formule la Constitución de la democracia? Me explico: en Chile las posturas están muy divididas. Para algunos solo sería legítima la Asamblea Constituyente; para otros, no puede haber reforma sin la participación del Congreso.

¿Qué opina usted sobre estas posturas? En definitiva, ¿cuál es su propuesta para garantizar que la Constitución de la democracia sea legítima?

J.T.: Nos referimos en especial a la idea de que es indispensable, según algunos sectores, obviar los procedimientos y quórum que establece la Constitución y crear, en ejercicio del poder soberano originario del pueblo, una Asamblea Constituyente. Este modo de proceder solo sería legal y legítimo si en una primera fase se modificara el Capítulo XV, sobre reforma constitucional, para dar lugar a la creación de la Asamblea Constituyente y el llamado a plebiscito para aprobar el trabajo de aquella. Aprovecho este espacio para hacer notar que la ciudadanía ha aprendido que, salvo el interludio dictatorial, el modo normal, natural y legítimo de reforma consiste en la interacción para crear normas superiores entre presidente de la República y cámaras legislativas. Por tanto, una buena parte del electorado reaccionará de todos modos de manera negativa a una iniciativa de facto para establecer una Asamblea Constituyente, dando a la nueva Constitución un sesgo de ilegitimidad para una importante parte del pueblo al momento mismo de su nacimiento, en lugar de ser la nueva Constitución una imagen y sello de legitimidad política y jurídica para toda la población del país y no solo para algunos sectores privilegiados. En suma, pese a que ha sido removida en buena parte la institucionalidad contramayoritaria, nunca ha sido tan difícil en Chile lograr consenso para reformar la Carta Fundamental, lo cual va en beneficio de los sectores conservadores y de derecha y en detrimento de la mayoría del pueblo, condenado mientras tanto a inimaginables niveles de desigualdad. Si la reforma se realiza conforme a los procedimientos que establece la Constitución actual, nadie objetará su legitimidad: el poder constituyente que se ejerce goza de buena 
legitimidad y salud. Si se insiste, por vías equivocadas, en encargar la reforma a una Asamblea Constituyente saltándose los procedimientos y quórum vigentes, la nueva Constitución será tachada como ilegítima por una parte importante de la población, cualquiera sea la sabiduría de su contenido. 